\title{
Y-box binding protein-1 and STAT3 independently regulate ATP-binding cassette transporters in the chemoresistance of gastric cancer cells
}

\author{
PEI JOU CHUA ${ }^{1 *}$, JIA PEI LIM ${ }^{1,2^{*}}$, TIAN TIAN GUO $^{1 *}$, PUJA KHANNA ${ }^{1}$, \\ QIDONG HU ${ }^{1}$, BOON HUAT BAY ${ }^{1}$ and GYEONG HUN BAEG ${ }^{1}$ \\ ${ }^{1}$ Department of Anatomy, Yong Loo Lin School of Medicine, National University of Singapore, Singapore 117594; \\ ${ }^{2}$ Translational Biomedical Proteomics Group, Institute of Molecular and Cell Biology, \\ Agency for Science, Technology and Research, Proteos 138673, Singapore
}

Received March 21, 2018; Accepted June 26, 2018

DOI: 10.3892/ijo.2018.4557

\begin{abstract}
Y-box binding protein-1 (YB-1) facilitates cancer chemoresistance through the upregulation of ATP-binding cassette $(\mathrm{ABC})$ transporters associated with multidrug resistance, which is one of the primary obstacles in cancer treatment. Since aberrant Janus kinase (JAK)/signal transducer and activator of transcription (STAT) signaling is also implicated in chemoresistance in numerous human malignancies, the interaction between YB-1 and JAK/STAT signaling was explored underlying the chemoresistance of NUGC3 gastric cancer cells. It was demonstrated that YB-1 translocated into the nuclei of NUGC3 cells exposed to doxorubicin hydrochloride, suggesting its important role in chemoresistance. Consistently, knockdown of $Y B-1$ significantly decreased the chemoresistance of cells to doxorubicin hydrochloride and epirubicin hydrochloride, as evidenced by a decrease in cell viability. Notably, JAK inhibitor AG490 treatment further decreased the cell viability caused by YB-1 inhibition and doxorubicin hydrochloride. It was also observed that YB-1 transcriptionally regulated the $A B C C 3$ transporter, whereas STAT3 modulated $A B C C 2$ transporter levels. These findings suggest that YB-1 and STAT3 act together to facilitate chemoresistance via modulating the expression of different ABC transporters in NUGC3 cells. Notably, siYB-1 did not exhibit any significant effect on STAT3 expression. Similarly, siSTAT3 failed to alter YB-1 expression, suggesting that the two may not regulate each other in a mutual manner. However,
\end{abstract}

Correspondence to: Professor Gyeong Hun Baeg, Department of Anatomy, Yong Loo Lin School of Medicine, National University of Singapore, MD10, 4 Medical Drive, Singapore 117594, Singapore

E-mail: antbgh@nus.edu.sg

*Contributed equally

Key words: Y-box binding protein-1, signal transducer and activator of transcription 3, chemoresistance, ATP-binding cassette transporter, gastric cancer double knockdown of $Y B-1$ and STAT3 led to a synergistic inhibition of cell invasion in NUGC3 cells. Nonetheless, the combined treatment of YB-1 antagonists with STAT3 inhibitors may serve as an effective therapy in gastric cancer.

\section{Introduction}

Chemotherapy is usually given systemically to patients with cancer following surgical intervention or radiotherapy (1). However, certain patients are unresponsive to chemotherapy whereby the cancer cells become resistance to chemotherapeutic drugs, a phenomenon known as multidrug resistance (MDR). MDR is resistance to multiple structurally and mechanistically unassociated classes of anticancer drugs by the cells (1), and has become a major impediment to cancer treatment due to cancer relapse which eventually leads to mortality.

Numerous reports have suggested a plausible association between MDR and Y-box binding protein-1 (YB-1), an evolutionary conserved DNA or RNA binding protein. YB-1 was initially discovered as a transcription factor that binds to the Y-box sequence (inverted CCAAT), present in the promoter region of the major histocompatibility complex class (MHC) II (2). It has pleotropic functions and is implicated in fundamental processes, including transcriptional regulation, DNA repair, mRNA splicing, translation and stability (3). The presence of nuclear YB-1 has been demonstrated as associated with enhanced transcription of the multidrug resistance 1 (MDRI) gene, eventually leading to the upregulation of P-glycoprotein, which is indicative of chemoresistance, cancer progression and poor prognosis (4). YB-1 was also suggested to be a promising prognostic biomarker for patients with breast cancer (5). A recent report has further suggested the involvement of YB-1 in cisplatin resistance in gastric cancer (6).

Janus kinase (JAK)/signal transducer and activator of transcription (STAT) signaling is an important pathway involved in fundamental cellular processes, including tumourigenesis, immune responses and sex determination (7-9). In particular, aberrant expression of STAT3 is associated with cancer progression through the facilitation of cell proliferation, 
metastasis and chemoresistance (10). Dysregulated STAT3 signaling has been implicated in gastric carcinogenesis $(11,12)$. Immunohistochemical staining of STAT3 in gastric adenocarcinoma tissues demonstrated that STAT3 serves as a predictor of poor prognosis and is associated with lymph node metastasis $(13,14)$. Disruption of STAT3 leads to a decrease in gastric cancer cell survival through a reduction in the expression of the anti-apoptotic molecule, survivin (15). Furthermore, inhibition of STAT3 has been reported to increase apoptosis in gastric cancer cells treated with cisplatin (16). Notably, the expression levels of STAT3 downstream targets, including B cell lymphoma-2 (Bcl-2) and c-Myc, were reported to be downregulated, while Bax and p53 levels were increased, elevating the sensitivity of gastric cancer cells to apoptosis (16).

As YB-1 and JAK/STAT signaling are known to enhance chemoresistance in gastric cancer, the present study aimed to determine whether they interact with each other to promote chemoresistance. The results of the current study suggested the involvement of YB-1 and STAT3 in the chemoresistance of gastric cancer NUGC3 cells, whereby the expression of multidrug resistance-associated proteins, $A B B C 3$ and $A B C C 2$, were transcriptionally regulated by YB-1 and STAT3, respectively. Notably, the inhibition of YB-1 and STAT3 activities were demonstrated to exhibit a synergistic effect on suppressing chemoresistance and cell invasion, suggesting that the combination of YB-1 antagonists with small molecule inhibitors of STAT3 may serve as an effective therapy for chemoresistance in gastric cancer.

\section{Methods and materials}

Cell culture. The poorly differentiated gastric adenocarcinoma cell line NUGC3 (American Type Culture Collection, Manassas, VA, USA) was routinely cultured in RPMI-1640 supplemented with $10 \%$ fetal bovine serum (FBS) (both form HyClone; GE Healthcare Life Sciences, Logan, UT, USA). When the cells were $80-90 \%$ confluent, subculturing of the cells were performed.

Short interfering RNA (siRNA/si) transfection. NUGC3 cells were plated in 6-well plates at a density of $2 \times 10^{5}$ cells/well. $Y B X 1, A B C C 2$ and $A B B C 3$ ON-TARGETplus SMARTpool siRNAs, as well as non-targeting pool siRNA were obtained from GE Healthcare Dharmacon, Inc. (Lafayette, CO, USA), while siRNA for STAT3 was obtained from Santa Cruz Biotechnology,Inc.(Dallas, TX,USA). Table I list the sequences of siRNAs used in the present study. NUGC3 cells were then transfected with $20 \mathrm{nM}$ of siNegative, siYB-1, siSTAT3, siABCC2 or siABCC3 using DharmaFECT1 Transfection reagent (GE Healthcare Dharmacon, Inc.). Following an overnight incubation with siRNAs, culture medium was replaced prior to further incubation. The transfected cells were then collected at $48 \mathrm{~h}$ post transfection for RNA isolation and $72 \mathrm{~h}$ post transfection for protein isolation. For double knockdown of STAT3 and $Y B-1$, each siRNA was used at a final concentration of $20 \mathrm{nM}$.

$R T-q P C R$. For RT-qPCR, $48 \mathrm{~h}$ following siRNA transfection, total RNA was extracted using the RNeasy Mini kit (Qiagen $\mathrm{GmbH}$, Hilden, Germany). A total of $1 \mu \mathrm{g}$ of

Table I. List of siRNA sequences used.

siRNA Target sequence (5'-3')

\section{NT siRNA \\ D-001810-10 \\ D-001810-11 \\ D-001810-12 \\ D-001810-13}

$Y B-1$ siRNA

J-010213-06

J-010213-07

J-010213-08

J-010213-09

$A B C C 2$ siRNA

J-004225-05

J-004225-06

J-004225-07

J-004225-08

$A B C C 3$ siRNA

J-007312-05

J-007312-06

J-007312-07

J-007312-08
UGGUUUACAUGUCGACUAA UGGUUUACAUGUUGUGUGA UGGUUUACAUGUUUUCUGA UGGUUUACAUGUUUUCCUA

CUGAGUAAAUGCCGGCUUA CGACGCAGACGCCCAGAAA

GUAAGGAACGGAUAUGGUU

GCGGAGGCAGCAAAUGUUA

GGAUGAAUCUCGACCCUUU GUAUCAGGUUUGCCAGUUA GGUCAAGUGUUCUACAGAU GAACCUGACUGUCUUCUUU

GGACAAAGGAGUAGUAGCU

GCACACCGGCUUAACACUA

CCACCCUGCUGAUACAGUA

ACAAUGAUCCAGUCACCUA

YB-1, Y-box binding protein-1; siRNA, small interfering RNA; ABC, ATP-binding cassette; NT, negative control.

total RNA was then used to synthesize first strand cDNA with the SuperScript III First-Strand Synthesis system (Invitrogen; Thermo Fisher Scientific, Inc., Waltham, MA, USA) as described previously (17). The HT7900 Fast Real-Time PCR system was used to examine alterations in gene expression using Fast SYBR-Green Master mix (both from Applied Biosystems; Thermo Fisher Scientific, Inc.). For the housekeeping gene, GAPDH was used for normalization. The thermocycling conditions used were as follows: initial activation at $95^{\circ} \mathrm{C}$ for $40 \mathrm{sec}$; and then 40 cycles consisting of melting at $95^{\circ} \mathrm{C}$ for $1 \mathrm{sec}$ and annealing/extension at $60^{\circ} \mathrm{C}$ for $20 \mathrm{sec}$. The $2^{-\Delta \Delta C q}$ method (18) was utilized to express the changes in gene expression and each sample was run in triplicate. Table II contains the list of primers used.

Western blot analysis. Total protein extraction and protein measurement were performed as previously described (17). Radioimmunoprecipitation lysis buffer (Pierce; Thermo Fisher Scientific, Inc.) was used to lyse the cells. Following Bradford protein assay quantification of the isolated proteins, $30 \mu \mathrm{g}$ of proteins were separated using a 8 or $10 \%$ SDS-PAGE gel, then transferred onto a polyvinyl difluoride membrane with a semi-dry system (Bio-Rad Laboratories, Inc., Hercules, CA, USA). Next, membranes were incubated with $5 \%$ bovine serum albumin (BSA) (Santa Cruz Biotechnology, Inc.), at room temperature for $1 \mathrm{~h}$, followed by incubation at $4^{\circ} \mathrm{C}$ overnight with the following primary antibodies: rabbit polyclonal anti-YB-1 [1:1,000; RIKEN, Wako-shi, Japan; $(17,19)$, 
Table II. List of primers used for RT-qPCR.

\begin{tabular}{|c|c|c|}
\hline Gene & Forward primer sequence $\left(5^{\prime} \rightarrow 3^{\prime}\right)$ & Reverse primer sequence $\left(5^{\prime} \rightarrow 3^{\prime}\right)$ \\
\hline$Y B-1$ & AAGTGATGGAGGGTGCTGAC & TTCTTCATTGCCGTCCTCTC \\
\hline STAT3 & ACCAGCAGTATAGCCGCTTC & GCCACAATCCGGGCAATCT \\
\hline GAPDH & GAAGGTGAAGGTCGGAGTCAACG & TGCCATGGGTGGAATCATATTGG \\
\hline$A B C C 1$ & ATGCTCACTTTCTGGCTGGTA & AGCGATCTGAGAAACAGGACA \\
\hline$A B C C 2$ & TATCCCACGAAGTGACAGAGG & ATGGTCGTCTGAATGAGGTTG \\
\hline$A B C C 3$ & GGACTTCCAGTGCTCAGAGG & TGGATGAGGTTGTCAGTCTCC \\
\hline$A B C C 4$ & TGTTCTTCTGGTGGCTCAATC & AGAACCCTTGCAACTCCTCTC \\
\hline$A B C C 5$ & CATCCGGACTACTTCCAAACA & CAGAGACCACACGTCTTCCAT \\
\hline$A B C G 2$ & AACTTCTGCCCAGGACTCAAT & CAGGTAGGCAATTGTGAGGAA \\
\hline
\end{tabular}

RT-qPCR, reverse transcription-quantitative polymerase chain reaction; YB-1, Y-box binding protein-1; ABC, ATP-binding cassette; STAT, signal transducer and activator of transcription.

the antibody was obtained from Dr Ken Matsumoto, who is stationed at RIKEN, Wako-shi.]; rabbit polyclonal anti-STAT3 (1:2,000; cat. no. 12640); rabbit polyclonal anti-phosphoSTAT3 (Ser727) (1:1,000; cat. no. 9134); rabbit polyclonal anti-phospho-STAT3 (Tyr705) (1:1,000; cat. no. 9145) (all from Cell Signaling Technology, Inc., Danvers, MA, USA); and mouse monoclonal anti- $\beta$-actin $(1: 6,000)$ (Sigma-Aldrich; Merck KGaA, Darmstadt, Germany; cat. no. A2228). Subsequent incubation of the membranes was performed with horseradish peroxidase-conjugated goat anti-rabbit IgG (1:5,000; Sigma-Aldrich, Merck KgaA; cat. no. A0545) or goat anti-mouse IgG (1:6,000; Sigma-Aldrich, Merck KgaA; cat. no. A9044) secondary antibodies at room temperature for $1 \mathrm{~h}$. Proteins were identified with SuperSignal West Pico Chemiluminescent ECL substrate (Pierce; Thermo Fisher Scientific, Inc.) and quantified by GS-800 optical densitometry with Quantity-One Image Analysis software version 4.62 (both from Bio-Rad Laboratories, Inc.).

Cell migration and invasion assays. Migration assays were performed with $6.5-\mathrm{mm}$ polycarbonate membrane Transwell inserts (Corning Incorporated, Corning, NY, USA), while BD BioCoat ${ }^{\mathrm{TM}}$ Matrigel $^{\mathrm{TM}}$ Invasion chambers (BD Biosciences, Franklin Lakes, NJ, USA) were used for the invasion assays. A total of $8 \times 10^{4}$ NUGC3 cells were seeded in $200 \mu \mathrm{l}$ of RPM1-1640 serum-free media in the upper part of the Transwell migration or invasion inserts, $48 \mathrm{~h}$ post siRNA transfection. Subsequently, $600 \mu 1$ of RPMI-1640 with $20 \%$ FBS was placed in the lower chamber of each well, which acted as a chemoattractant for the cells. The cells were then allowed to migrate or invade for 20 or $48 \mathrm{~h}$, respectively, prior to fixation with absolute methanol for $3 \mathrm{~min}$ and stained with $0.5 \%(\mathrm{w} / \mathrm{v})$ crystal violet in $20 \%$ methanol for $30 \mathrm{~min}$ at room temperature. Inserts were then washed with distilled water. Next, the upper membrane of the inserts were wiped with wet cotton swabs to remove cells that did not migrate or invade. To visualize migrated or invaded NUGC3 cells, images of five different fields were captured with a Nikon SMZ 1500 stereo microscope (Nikon Corporation, Tokyo, Japan) at x100 magnification and stained cells were counted. The assay was performed in triplicates.
Determination of inhibitory concentration $\left(I C_{50}\right)$ of chemotherapy drugs. NUGC3 cells were grown at $4 \times 10^{4}$ cells/well in a 24-well plate, and transfected with siNegative or siYB-1 after $24 \mathrm{~h}$ post seeding using the aforementioned protocol. Then, following transfection for $48 \mathrm{~h}$, treatment with varying concentrations of doxorubicin hydrochloride $(0,0.3125,0.625$, $1.25,2.5$ and $5 \mu \mathrm{M})$ or epirubicin hydrochloride $(0,0.3125$, $0.625,1.25,2.5,10$ and $20 \mu \mathrm{M}$ ) (both from Sigma-Aldrich; Merck KGaA) was performed. The corresponding percentages of cell viability at different concentrations of drugs were determined by MTS assay, after $24 \mathrm{~h}$ incubation. Subsequently, $600 \mu \mathrm{l}$ of MTS mixture (diluted 1:5 in RPMI-1640 with $10 \%$ FBS; Promega Corporation, Madison, WI, USA) were added to each of the wells. A negative control set of blank wells containing only MTS solution with no cells was also prepared. Incubation of cells was performed in the dark at $37^{\circ} \mathrm{C}$ for $4 \mathrm{~h}$. CellTiter $96^{\circledR}$ AQueous One Solution Cell Proliferation assay reagent (Promega Corporation) was added to cells to measure cell viability. A wavelength of $490 \mathrm{~nm}$ was used for measuring of the absorbance with an ELISA plate reader. The $\mathrm{IC}_{50}$ value of each drug was then determined by plotting the survival rate after $24 \mathrm{~h}$ of drug treatment against varying drug concentrations.

Transmission electron microscopy (TEM). The effect of doxorubicin treatment in NUGC3 cells was evaluated using TEM. NUGC3 cells were treated with $\mathrm{IC}_{50}$ of doxorubicin for $48 \mathrm{~h}$. Cells in the supernatant were obtained by centrifugation at $1,000 \mathrm{x} \mathrm{g}$ for $5 \mathrm{~min}$ at room temperature and adherent cells were detached and then collected by centrifuging at $300 \mathrm{xg}$ for $5 \mathrm{~min}$ at room temperature. Then, $2.5 \%$ glutaraldehyde was used to fix the cell pellets for $1 \mathrm{~h}$ at room temperature, prior to washing with $1 \mathrm{X}$ PBS thrice and post-fixation with $1 \%$ osmium tetroxide (Agar Scientific Ltd., Stansted, UK) for $1 \mathrm{~h}$ at room temperature. Following dehydration with increasing concentrations of ethanol, the pellet was embedded in araldite. The fixation in araldite was performed at $40^{\circ} \mathrm{C}$ for $45 \mathrm{~min}$, then $50^{\circ} \mathrm{C}$ for $30 \mathrm{~min}$ and finally $55^{\circ} \mathrm{C}$ or $30 \mathrm{~min}$. The samples were sectioned and mounted on a copper grid coated with formvar. Sections of the samples were stained with uranyl acetate for $10 \mathrm{~min}$ and lead citrate for $8 \mathrm{~min}$, both at 
room temperature and finally viewed under a Philips CM120 BioTwin TEM (FEI; Thermo Fisher Scientific, Inc.) at x2,800 or $\mathrm{x} 4,400$ magnifications.

Immunofluorescence staining. NUGC3 cells were grown on a Lab-Tek 4-Chambered coverglass (Nalge Nunc International; Thermo Fisher Scientific, Inc.) until $60-70 \%$ confluency was achieved. For cell fixation, cells were incubated with $4 \%$ paraformaldehyde for $20 \mathrm{~min}$ at room temperature. Subsequently, $0.05 \%$ Tween-20/PBS was used for washing twice, followed by permeabilisation with $0.2 \%$ Triton-X/PBS for $5 \mathrm{~min}$ and blocking with $1 \%(\mathrm{w} / \mathrm{v}) \mathrm{BSA}$ at room temperature for $30 \mathrm{~min}$. The YB-1 primary antibody (1:250) (17) was diluted in $1 \% \mathrm{BSA}(\mathrm{w} / \mathrm{v}) 1 \mathrm{XPBS}$ and incubated at $4^{\circ} \mathrm{C}$ overnight. Washing was performed thrice with $0.05 \%$ Tween-20/PBS. Next, cells were incubated with goat anti-rabbit IgG Alexa Fluor 594 secondary antibody (1:400; cat. no. A11012; Thermo Fisher Scientific, Inc.) at room temperature in the dark for $1 \mathrm{~h}$. The cover glass was removed following washing thrice again with $0.05 \%$ Tween-20/PBS and mounted on a coverslip with VECTASHIELD fluorescent mounting medium containing DAPI (Vector Laboratories., Burlingame, CA, USA), which counterstains the nucleus. Subsequently, an Olympus Fluoview FV1000 Laser Scanning confocal microscope (Olympus Corporation, Tokyo, Japan) was used to visualize the stained cells at $\mathrm{x} 400$ or $\mathrm{x} 600$ magnifications.

For siYB-1, siSTAT3 or siNegative transfected-NUGC3 cells, immunofluorescence staining was performed on the cover slips with seeded cells at $48 \mathrm{~h}$ post transfection. The primary antibodies used were anti-phospho-STAT3 (Tyr705) (1:50), anti-total STAT3 (1:1,000) (both from Cell Signaling Technology, Inc.) and anti-YB-1 (1:250) (17), followed by the use of goat anti-rabbit IgG Alexa Fluor 594 (1:400) (cat. no. A11012) or goat anti-rabbit IgG Alexa Fluor 488 (1:400) (both from Thermo Fisher Scientific, Inc.; cat. no. A11008) secondary antibodies. The procedures were the same as aforementioned with the exception that the cells were fixed with $100 \%$ methanol for 20 min for immunofluorescence staining of phospho-STAT3 (Tyr705) and total STAT3 at room temperature.

Cotreatment of the JAK inhibitor AG490 and doxorubicin hydrochloride, following YB-1 knockdown in NUGC3 cells. Cell were transfected as aforementioned for $48 \mathrm{~h}$ and 0 or $50 \mu \mathrm{M}$ AG490 was used for the $48 \mathrm{~h}$ treatment, prior to exposure to medium with or without $\mathrm{IC}_{50}$ of doxorubicin hydrochloride for $24 \mathrm{~h}$. Subsequently, an MTS assay was performed to determine cell viability.

Doxorubicin hydrochloride treatment in siABCC2 and siABCC3 NUGC3 cells. NUGC3 cells were grown in a 24-well plate at a density of $4 \times 10^{4}$ cells/well, followed by treatment with siABCC2, siABBC3 or siNegative, to a final concentration of $20 \mathrm{nM}$, with the aforementioned transfection procedures. At $48 \mathrm{~h}$ post transfection, treatment with doxorubicin hydrochloride for $24 \mathrm{~h}$ was performed, then cell viability was evaluated using an MTS assay.

Statistical analysis. The GraphPad Prism 5.0 (GraphPad Software, Inc., La Jolla, CA, USA) statistical package was used.
For the means between two groups, a two tailed Student's t-test was used; whereas for comparison between $\geq 3$ groups, one-way analysis of variance was used followed by Tukey's post-hoc test. Data are presented as mean \pm standard error of the mean. $\mathrm{P}<0.05$ was considered to indicate a statistically significant difference. All experiments were repeated in triplicates.

\section{Results}

$Y B-1$ protein translocalizes to the nucleus upon chemotherapy treatment in NUGC3 cells. Several reports have suggested that chemotherapeutic drugs kill cancer cells susceptible to the treatment through promoting apoptosis, and have implicated nuclear YB-1 in chemoresistance (19-21). Hence, whether the treatment of NUGC3 cells with chemotherapy drugs, including doxorubicin hydrochloride were able to induce cell death was examined. NUGC3 cells treated with doxorubicin hydrochloride at a concentration of $4.65 \mu \mathrm{M}\left(\mathrm{IC}_{50}\right)$ (data not shown) for $48 \mathrm{~h}$ exhibited morphological changes, including cytoplasmic blebbing (Fig. 1A; black arrows), indicative of apoptosis. Subsequently, whether nuclear translocation of YB-1 increased upon doxorubicin hydrochloride treatment was investigated. Notably, a marked increase in the levels of nuclear YB-1 was detected upon doxorubicin hydrochloride compared with the control, suggesting the potential role of YB-1 in chemoresistance (Fig. 1B).

Knockdown of YB-1 decreases chemoresistance of NUGC3 cells. To investigate whether YB-1 functions in chemoresistance of gastric cancer NUGC3 cells, the inhibitory effects of YB-1 on cell viability, following exposure to chemotherapy drugs were evaluated. The siRNA-mediated silencing efficiency of YB-1 at the mRNA and protein levels was $\sim 99$ and 56\%, respectively (Fig. 2A and B). Notably, inhibition of YB-1 induced a decrease in chemoresistance of the cells to doxorubicin hydrochloride and epirubicin hydrochloride, two of the commonly used chemotherapy drugs for cancer treatment. While the $\mathrm{IC}_{50}$ of doxorubicin hydrochloride in NUGC3 cells transfected with siYB-1 was $2.8 \mu \mathrm{M}$, the $\mathrm{IC}_{50}$ of doxorubicin hydrochloride in control cells was $7.2 \mu \mathrm{M}$ (Fig. 2C). Similarly, the $\mathrm{IC}_{50}$ of epirubicin hydrochloride in cells transfected with siYB-1 was decreased compared with control cells (2.1 vs. $6.3 \mu \mathrm{M})$; however, this was not statistically significant (Fig. 2D).

Synergistic inhibitory effects of $Y B-1$ and JAK/STAT signaling on chemoresistance. The JAK/STAT signaling pathway has also been implicated in the chemoresistance of cancer cells $(10,22,23)$. For example, STAT3-dependent myeloid cell leukemia-1 (Mcl-1) expression was reported to affect chemosensitivity in melanoma, whereby Mcl-1 confers survival advantage against B-Raf proto-oncogene serine/threonine kinase inhibitors (24). Therefore, the present study examined the potential interaction between JAK/STAT signaling and YB-1 in the chemoresistance of NUGC3 cells. The viability of siNegative-transfected control cells co-treated with the JAK2 inhibitor AG490 and doxorubicin hydrochloride compared with that of the control cells treated with AG490 or doxorubicin hydrochloride alone was examined. As shown in Fig. 3, AG490 or doxorubicin hydrochloride treatment alone 
A

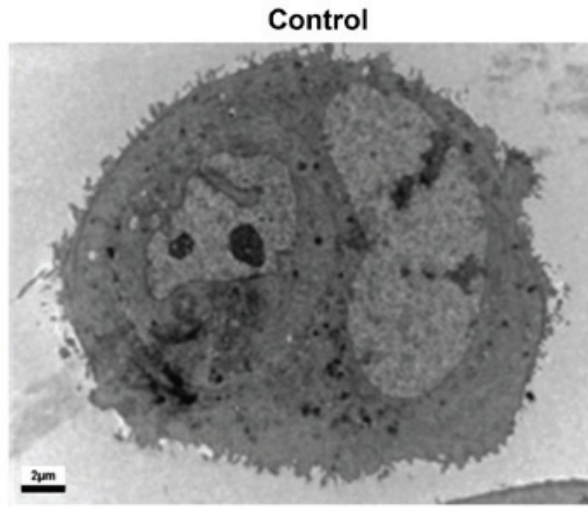

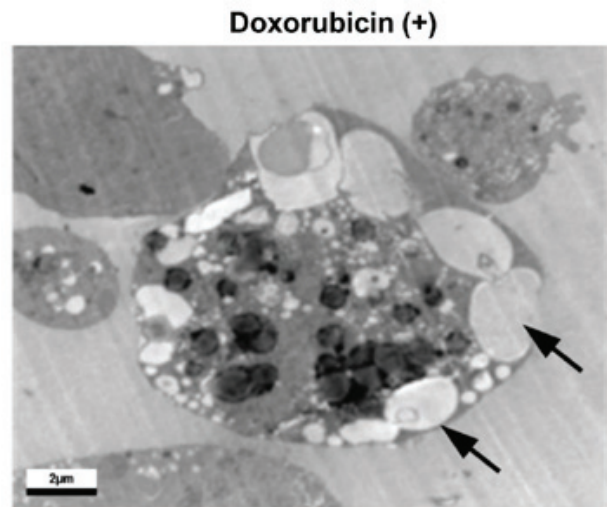

Doxorubicin (+) (merged)
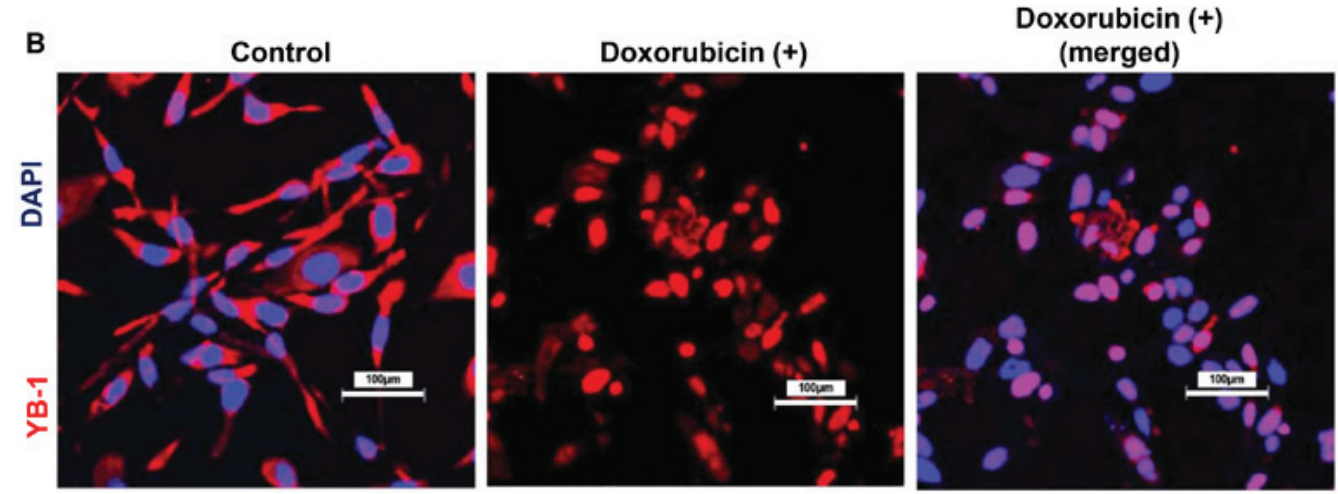

Figure 1. YB-1 translocates to the nucleus upon chemotherapy drug treatment. (A) Transmission electron microscopy micrographs of NUGC3 cells treated with $\mathrm{IC}_{50}$ of doxorubicin hydrochloride for $48 \mathrm{~h}$ revealed that the cells underwent apoptosis-like changes, as evidenced by cytoplasmic blebbing (right, black arrows), as compared with untreated cells (left). Scale bar, $2 \mu \mathrm{m}$. (B) Immunofluorescence staining for YB-1 in NUGC3 cells treated with doxorubicin hydrochloride. In untreated cells, YB-1 was primarily located in the cytoplasm (left), but YB-1 translocated to the nucleus upon doxorubicin hydrochloride treatment (middle). Scale bar, $100 \mu \mathrm{m}$. YB-1, Y-box binding protein-1.

reduced the viability of cells compared with the untreated control group. Notably, co-treatment of AG490 and doxorubicin hydrochloride further enhanced the decreased viability induced by AG490 or doxorubicin hydrochloride. The effects of co-treatment with AG490 and doxorubicin hydrochloride on cell viability were examined in $Y B-1$ knockdown cells. Cell death in $Y B-1$ knockdown cells treated with AG490, doxorubicin hydrochloride, or AG490 and doxorubicin hydrochloride, was further enhanced compared with that in siNegativetransfected control cells treated with AG490, doxorubicin hydrochloride, or AG490 and doxorubicin hydrochloride, respectively. These suggest that JAK/STAT signaling and YB-1 function synergistically in promoting chemoresistance of gastric cancer cells to doxorubicin hydrochloride.

$Y B-1$ and STAT3 regulate the expression of different $A B C$ transporters. To obtain insight into the possible interaction between YB-1 and JAK/STAT signaling in chemoresistance, the effect of $Y B-1$ knockdown on STAT3 expression and vice versa was evaluated. However, no significant changes were observed in total STAT3 and phosphorylated STAT3 (Tyr705 and Ser727) levels upon $Y B-1$ knockdown in NUGC3 cells (Fig. 4A, upper panel). Furthermore, immunofluorescence staining of siYB-1-transfected NUGC3 cells revealed no significant changes in the subcellular localization of phosphorylated STAT3 (Tyr705) and total STAT3 in the nucleus (Fig. 4A, lower panel). Similarly, STAT3 knockdown did not significantly affect YB-1 expression (Fig. 4B, upper panel) or the subcellular localization of YB-1 in the nucleus (Fig. 4B, lower panel).

As ABC transporters are implicated in multidrug resistance in various cancer types (25-28), the present study aimed to evaluate the regulatory effect of YB-1 and STAT3 on $\mathrm{ABC}$ transporters, as the two proteins act as transcriptional factors. Upon $Y B-1$ knockdown in NUGC3 cells, a significant reduction in the $A B B C 3$ transporter gene was observed out of the six different ABC transporters ( $A B C C 1, A B C C 2$, $A B C C 3, A B C C 4, A B C C 5$ and $A B C G 2$ ) evaluated (Fig. 5A). However, STAT3 knockdown only led to a significant decrease in $A B C C 2$ expression (Fig. 5A). These results suggest that YB-1 and STAT3 act independently in chemoresistance by regulating the expression of different $\mathrm{ABC}$ transporters, which serve essential roles in multidrug resistance in various cancer types. The possible synergistic effects of YB-1 and STAT3 on $\mathrm{ABC}$ transporter expression were also examined. However, no significant synergistic effects were observed, confirming that YB-1 and STAT3 functions independently in regulating the expression of $\mathrm{ABC}$ transporters.

The role of $\mathrm{ABCC} 2$ and $\mathrm{ABCC} 3$ on the viability of NUGC3 cells treated with doxorubicin hydrochloride was then examined. The knockdown efficiencies of siABCC3 and siABCC2 were 59.9\% (Fig. 5B, left panel) and 56.5\% (Fig. 5B, right panel), respectively. $A B C C 3$ knockdown in NUGC3 cells led to decreased cell viability upon doxorubicin hydrochloride treatment, as compared with the negative control (Fig. 5C, left panel). However, no significant reduction in the viability of 
A

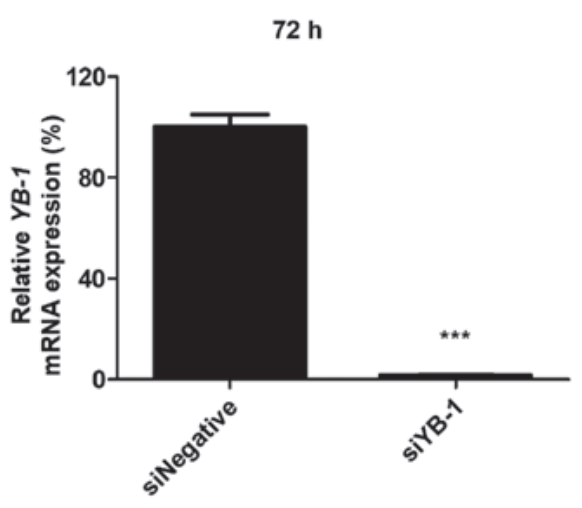

C Doxorubicin hydrochloride

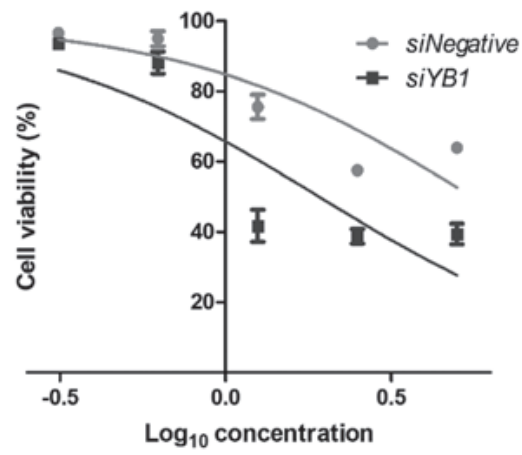

B

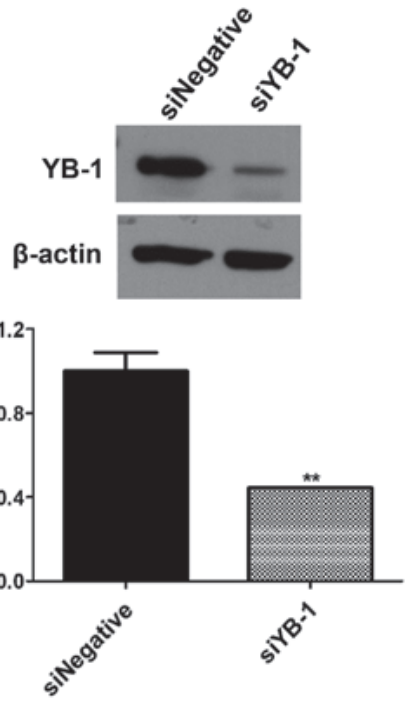

D Epirubicin hydrochloride

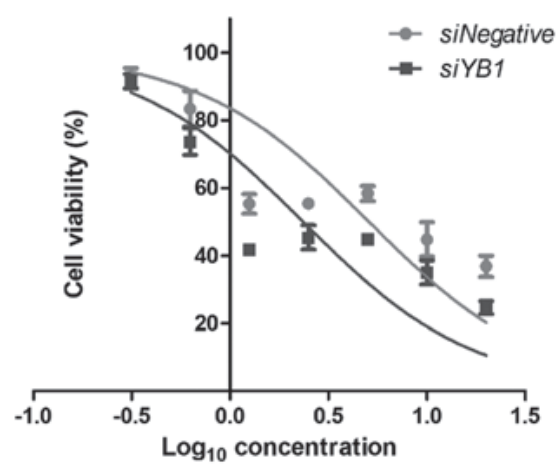

Figure 2. $Y B-1$ knockdown suppresses chemoresistance of NUGC3 cells. $Y B-1$ knockdown caused a significant decrease in $Y B-1$ mRNA (A) and protein (B) levels, as compared with the controls at $72 \mathrm{~h}$ post siRNA transfection. Representative dose response curves illustrate that the viability of NUGC3 cells treated with doxorubicin hydrochloride (C) or epirubicin hydrochloride (D) further decreased upon $Y B-1$ knockdown compared with the controls. Data are presented as the mean \pm standard error of the mean from three independent experiments, ${ }^{* *} \mathrm{P}<0.01$ and ${ }^{* * *} \mathrm{P}<0.001$. YB-1, Y-box binding protein-1; si, small interfering RNA.

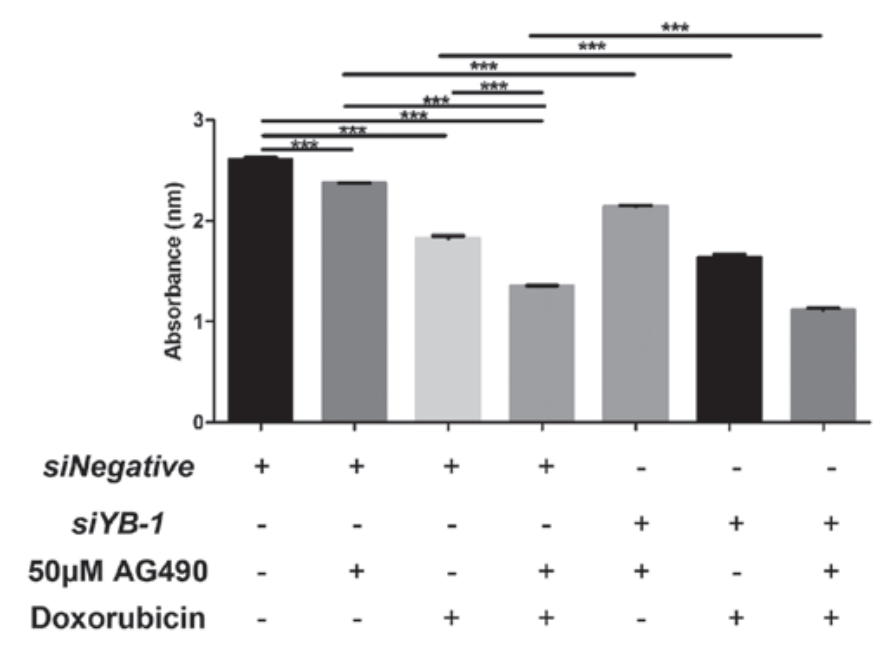

Figure 3. Synergistic effect of YB-1 and JAK/STAT signaling on chemoresistance. Note that co-treatment of the JAK inhibitor AG490 and doxorubicin hydrochloride enhanced the decreased viability caused by AG490 at $50 \mu \mathrm{M}$ or $\mathrm{IC}_{50}$ of doxorubicin hydrochloride alone. Notably, cell death in siNegative-transfected control cells treated with AG490, doxorubicin hydrochloride or AG490 and doxorubicin hydrochloride, was further enhanced upon $Y B-1$ knockdown, suggesting the key role of YB-1 in chemoresistance. Data are presented as the mean \pm standard error of the mean from three independent experiments, ${ }_{* * * *} \mathrm{P}<0.001$. YB-1, Y-box binding protein-1; si, small interfering RNA; JAK, Janus kinase; STAT, signal transducer and activator of transcription.
$A B C C 2$ knockdown cells was observed upon treatment with doxorubicin hydrochloride (Fig. 5C, right panel).

YB-1 and STAT3 exhibit synergistic effects on facilitating cell invasion in NUGC3 cells. As previously mentioned, YB-1 and STAT3 exhibited a synergistic effect in mediating chemoresistance of NUGC3 cells (Fig. 3). Hence, the effects of their combination on cell migration and invasion were investigated. A double knockdown of $Y B-1$ and STAT3 was performed in NUGC3 cells. STAT3 knockdown alone significantly decreased cell migration as compared with the control. $Y B-1$ knockdown alone also led to a decline in cell migration, albeit statistically insignificant. The double knockdown of YB-1 and STAT3 failed to further enhance the decrease caused by STAT3 knockdown alone, suggesting that there was no synergistic effect on cell migration (Fig. 6A). In contrast, the double knockdown of $Y B-1$ and STAT3 in NUGC3 cells further inhibited cell invasion caused by $Y B-1$ or STAT3 knockdown alone (Fig. 6B), suggesting the synergistic role of YB-1 and STAT3 in cell invasion.

\section{Discussion}

YB-1 is a pleotropic protein which is upregulated in numerous human malignancies, including gastric cancer (29), naso- 
A

YB-1 mRNA expression

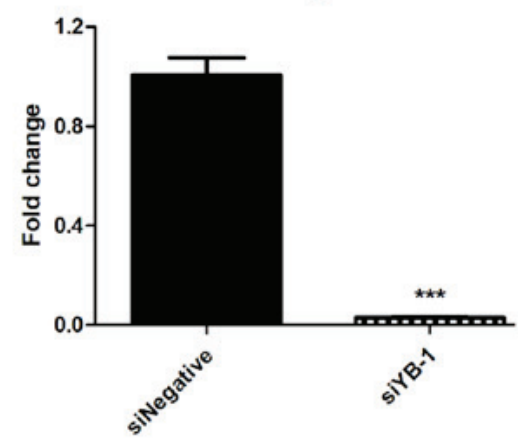

siNegative
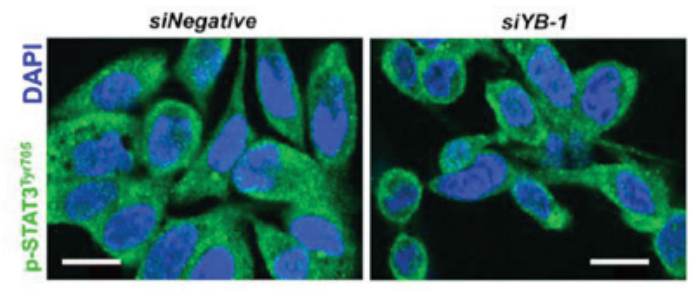

STAT3 mRNA expression

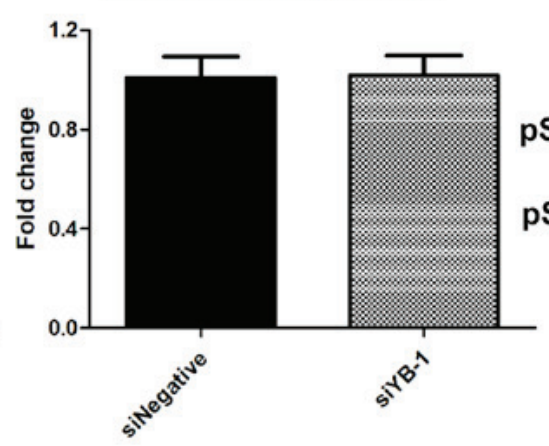

siNegative

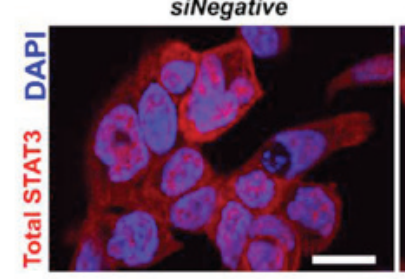

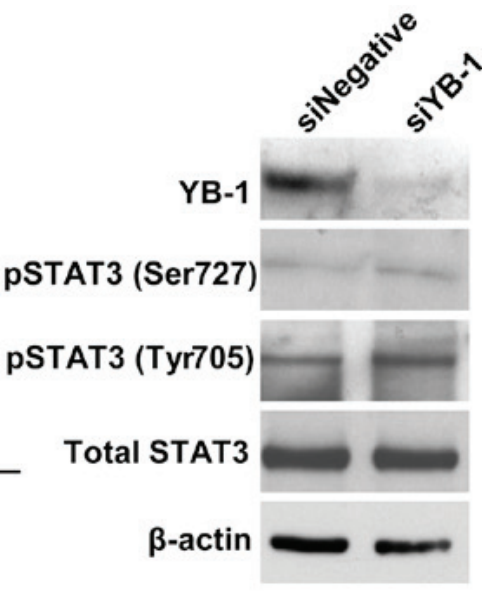

siYB-1

B STAT3 mRNA expression

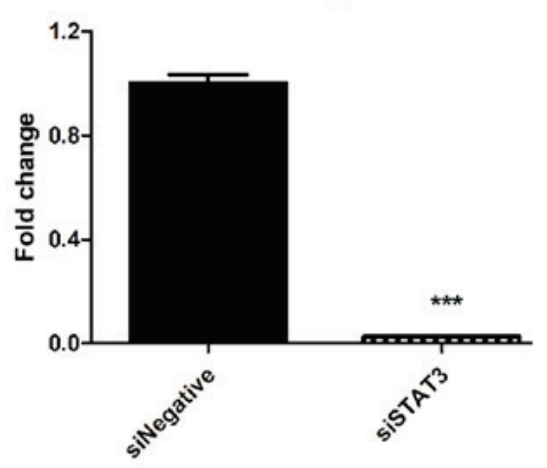

YB-1 mRNA expression

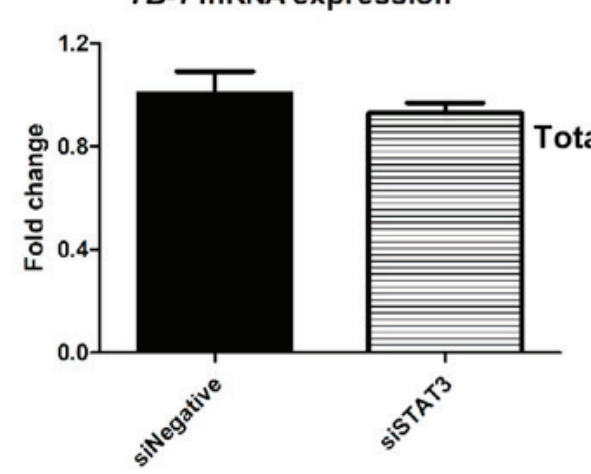

Total STAT3

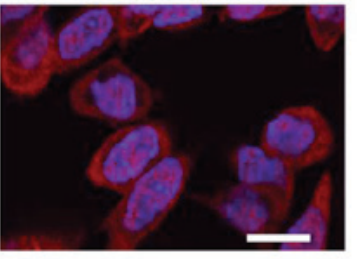

siNegative
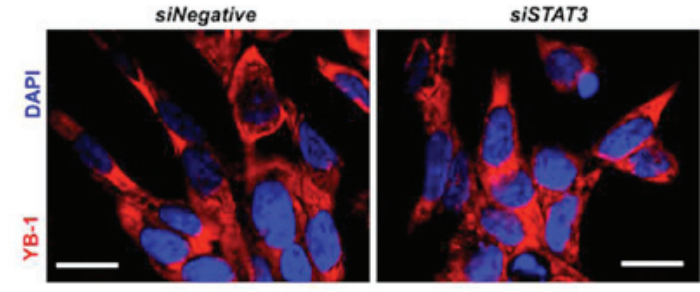

Figure 4. Expression of YB-1 and STAT3 is not mutually regulated. (A) $Y B-1$ and STAT3 mRNA levels upon $Y B-1$ knockdown (upper left and middle panels). No significant changes in STAT3 mRNA were detected when YB-1 was inhibited in NUGC3 cells. YB-1 knockdown also failed to affect total and phosphorylated STAT3 levels (upper right panel). Similarly, immunofluorescence staining of phospho-STAT3 (Tyr705) and total STAT3 demonstrated no changes in their subcellular localization upon $Y B-1$ knockdown (lower panel). (B) STAT3 knockdown resulted in a significant decrease in STAT3 mRNA levels, but not YB-1 mRNA levels (upper left and middle panels). Consistently, STAT3 inhibition did not affect YB-1 expression (upper right panel). Immunofluorescence staining revealed no changes in the subcellular localization of YB-1 upon STAT3 knockdown (lower panel). Data are presented as the mean \pm standard error of the mean from three independent experiments, ${ }^{* * *} \mathrm{P}<0.001$. Scale bar, $20 \mu \mathrm{m}$. YB-1, Y-box binding protein-1; si, small interfering RNA; JAK, Janus kinase; STAT, signal transducer and activator of transcription; $p$, phosphorylated.

pharyrngeal carcinoma (19) and breast cancer (17). YB-1 has been reported to serve a vital role in MDR in patients with cancer $(4,30)$. Under normal conditions, YB-1 is predominantly expressed in the cytoplasm (31), but translocates to the nucleus upon exposure to environmental stress, including UV light, drug treatment and hyperthemia $(4,31)$. Furthermore, the YB-1 nuclear localization is associated with $M D R l$ gene expression, whose product mediates chemoresistance in various cancer types, including breast, synovial sarcoma and osteosarcoma cancer (3). In line with the potential role of YB-1 in chemoresistance in various cancer types, including nasopharyngeal cancer (19), breast cancer (21), melanoma (32) and ovarian cancer (33), the present study demonstrated the cytoplasmic to nuclear translocation of YB-1 in the NUGC3 gastric cancer cell line upon doxorubicin hydrochloride treatment. In support of this, $Y B-1$ reduction led to a significant decrease in the chemoresistance of NUGC3 cells to doxorubicin hydrochloride and epirubicin hydrochloride. 
A

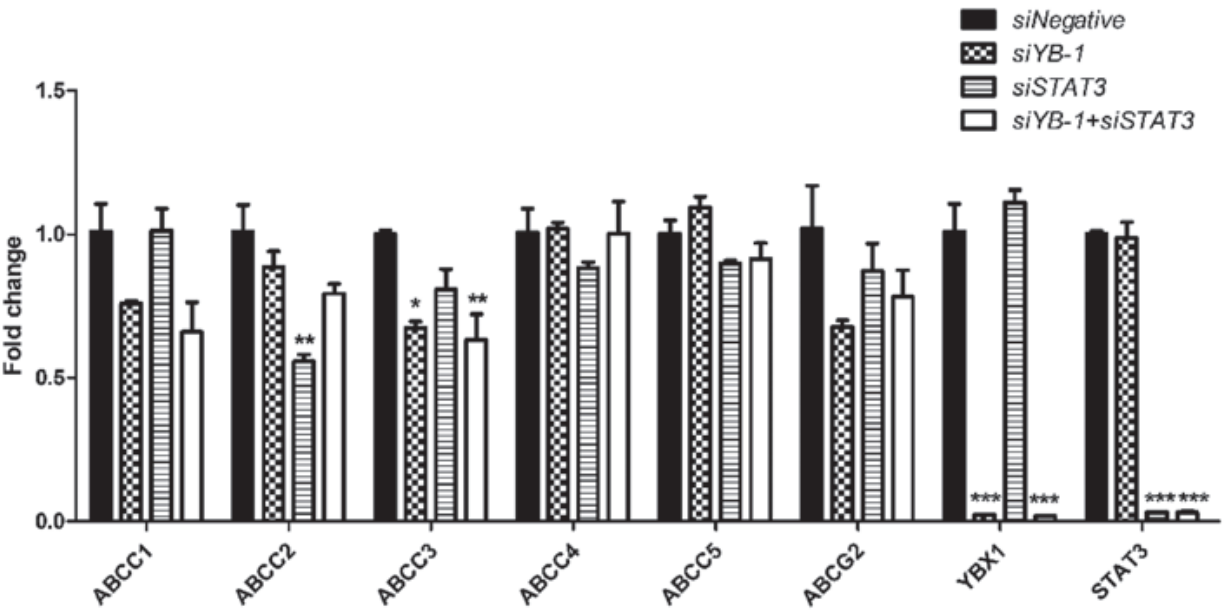

B
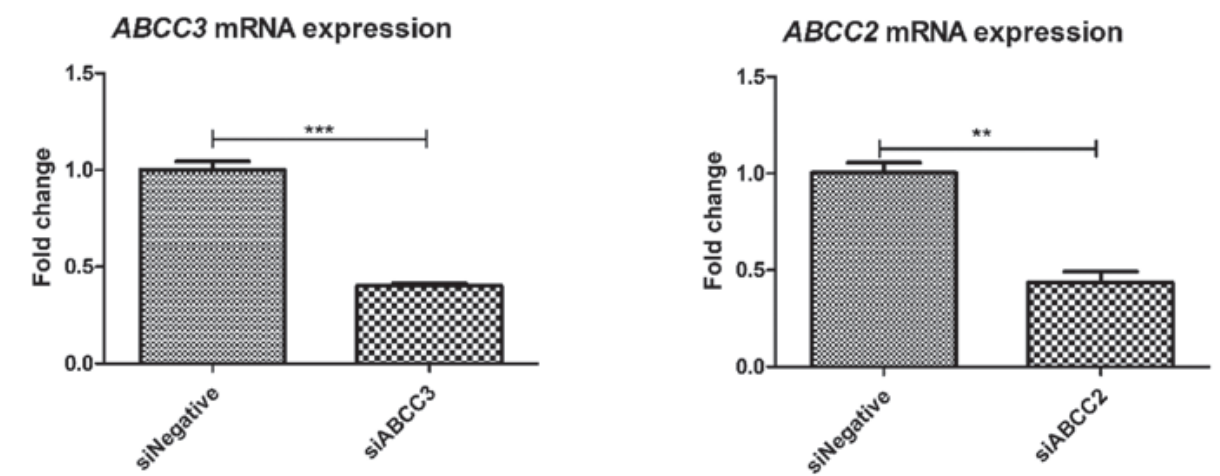

C
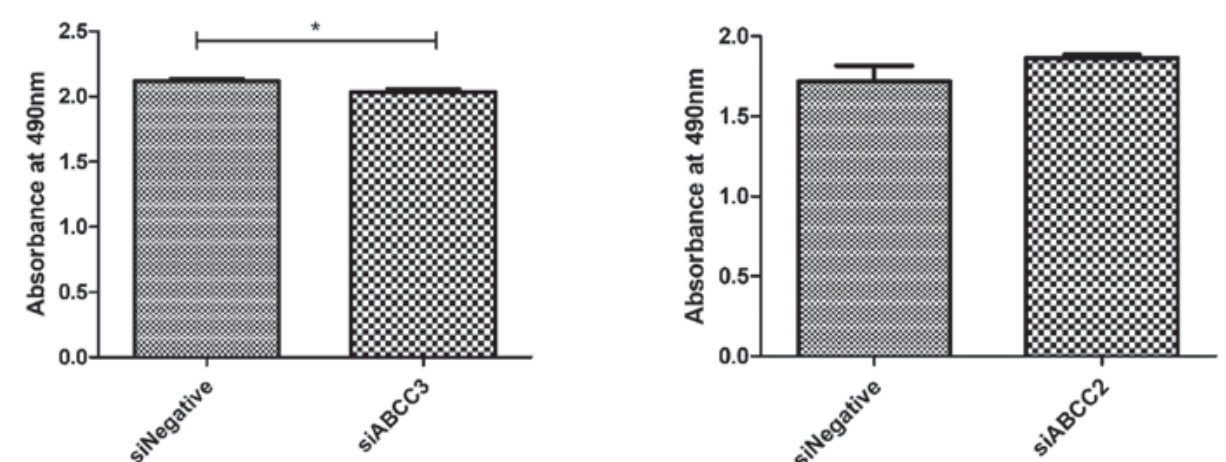

Figure 5. YB-1 and STAT3 function to regulate the expression of ABC transporters. (A) ABC transporter gene expression in NUGC3 cells. YB-1 knockdown led to a significant downregulation of $A B C C 3$ in NUGC3 cells, while $S T A T 3$ knockdown decreased the expression of $A B C C 2$. (B) The knockdown efficiencies of siABCC3 (left panel) and siABCC2 (right panel) at mRNA levels. (C) Cell viability of NUGC3 cells upon knockdown of $A B C C 3$ (left panel) or $A B C C 2$ (right panel), in the presence of doxorubicin hydrochloride. Data are presented as the mean \pm standard error of the mean from three independent experiments. ${ }^{*} \mathrm{P}<0.05,{ }^{* *} \mathrm{P}<0.01$ and ${ }^{* * *} \mathrm{P}<0.001$, compared with the siNegative group. YB-1, Y-box binding protein-1; ABC, ATP-binding cassette; STAT, signal transducer and activator of transcription; si, small interfering RNA.

Notably, constitutively-active JAK/STAT signaling has also been demonstrated to be associated with gastric cancer development and progression (34). In particular, it has been reported that STAT3 is phosphorylated by JAK, which subsequently translocates to the nucleus, and acts as a transcription factor to modulate the expression of a wide variety of genes that participate in proliferation, migration as well as invasion in gastric cancer cells $(35,36)$. STAT3 also promotes anti-apoptotic molecule expression, including Bcl-2 and Mcl-1, thereby conferring pro-survival signals in gastric cancer cells (16). Furthermore, it serves as a useful biomarker in gastric cancer prognosis (37), with a high expression of STAT3 identified in gastric cancer (15).
YB-1 and JAK/STAT signaling have been implicated in chemoresistance $(7,20)$. Hence, a possible synergistic effect of YB-1 and JAK/STAT signaling on chemoresistance was examined using siYB-1 and the JAK2 inhibitor AG490 in gastric cancer NUGC3 cells. Notably, an enhanced reduction in the viability of NUGC3 cells co-treated with siYB-1 and AG490 in the presence of doxorubicin hydrochloride was observed, as compared with the viability in cells treated with siYB-1 or AG490 alone upon doxorubicin hydrochloride treatment. Thus, these results suggest that YB-1 and JAK/STAT signaling are involved in chemoresistance, and may act synergistically to promote chemoresistance of gastric cancer. To obtain more insight into the mechanism underlying 
A

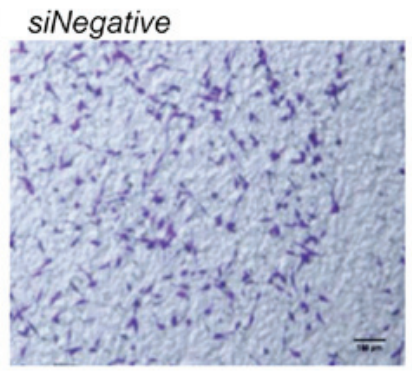

SISTAT3

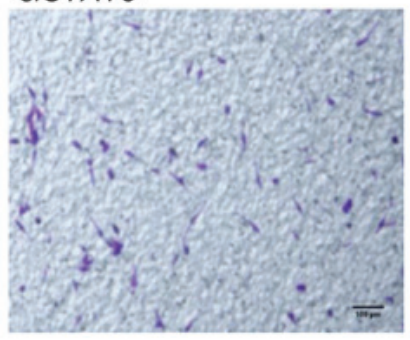

B

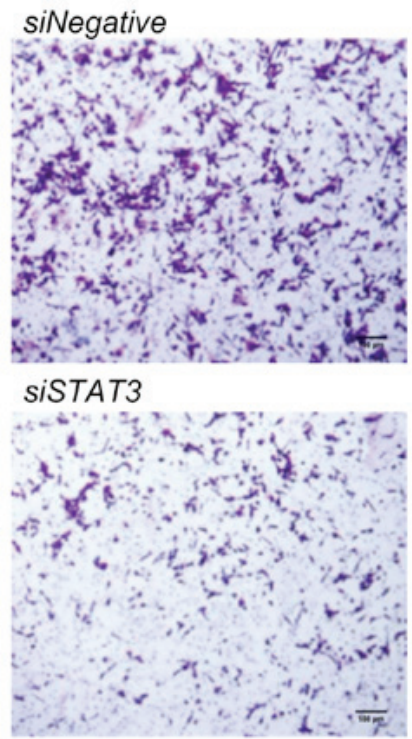

siYB-1

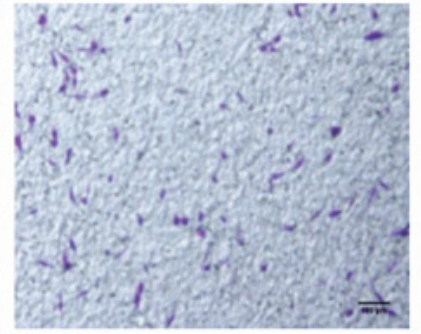

SIYB-1+ siSTAT3
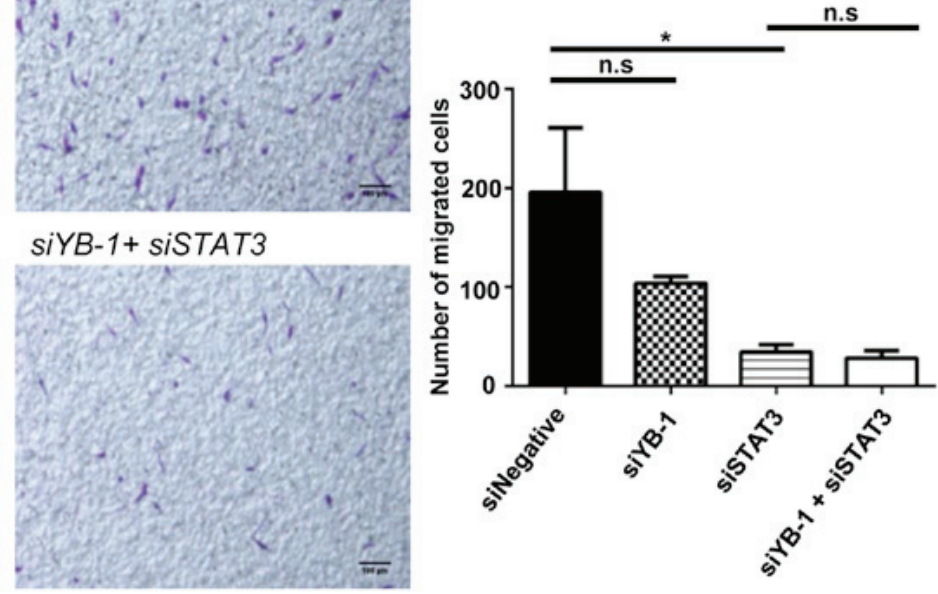

siYB-1

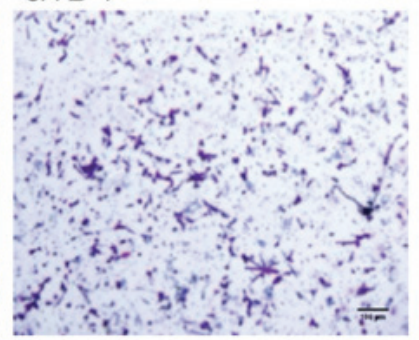

SIYB-1+ SISTAT3

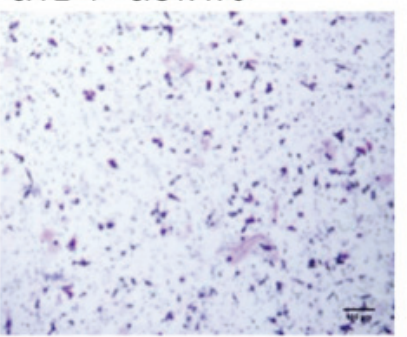

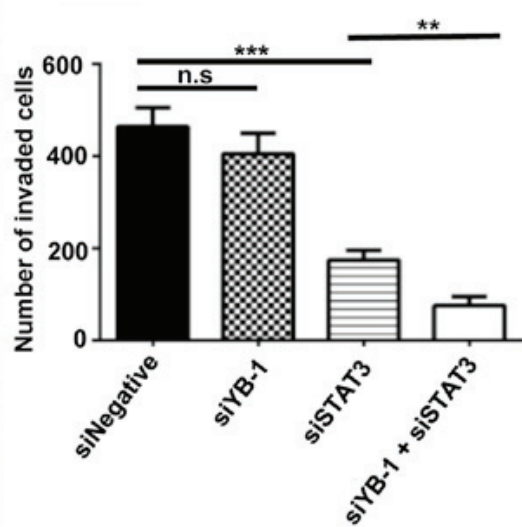

Figure 6. YB-1 and STAT3 synergistically act to decrease cell invasion in NUGC3 cells. (A) STAT3 knockdown resulted in a decrease in cell migration as compared with the control. However, no synergistic inhibitory effect of YB-1 on STAT3 knockdown-mediated decrease in cell migration was observed. (B) Double knockdown of YB-1 and STAT3 further inhibited cell invasion caused by YB-1 or STAT3 knockdown alone, suggesting that YB-1 and STAT3 act together to promote cell invasion in NUGC3 cells. Data are presented as the mean \pm standard error of the mean from three independent experiments, "P $<0.05$, ${ }^{* *} \mathrm{P}<0.01$ and ${ }^{* * *} \mathrm{P}<0.001$. Scale bar, $100 \mu \mathrm{m}$. YB-1, Y-box binding protein-1; ABC, ATP-binding cassette; STAT, signal transducer and activator of transcription; si, small interfering RNA.

their synergistic effects on chemoresistance, the inhibitory effect of YB-1 on STAT3 levels was ascertained. However, no alterations in total STAT3 and phosphorylated STAT3 levels upon $Y B-1$ knockdown were detected. Similarly, STAT3 knockdown did not lead to any striking changes in YB-1 expression. YB-1 inhibition was shown to decrease phosphorylated STAT3 (Ser727) levels, but not phosphorylated STAT3 (Tyr705) or total STAT3 levels in breast cancer cells (38). This may suggest the cell type-dependent effect of YB-1 on STAT3 activity. Nonetheless, gene expression analysis of MDR-associated genes and ABC transporters upon siYB-1 or siSTAT3 revealed differential gene regulations, whereby YB-1 regulates $A B C C 3$ expression while STAT3 regulates $A B C C 2$ expression. In addition, no synergistic effects were observed for YB-1 and STAT3 on the ABC transporters, further suggesting that YB-1 and STAT3 regulate the expression of ABC transporters independently.

Regarding the role of $A B C C 2$ and $A B C C 3$ in chemoresistance, siRNA mediated knockdown of the two $A B C$ transporters was then performed. Cell viability was reduced to an extent in doxorubicin hydrochloride treated siABCC3 NUGC3 cells, but not in siABCC2 cells. The possible explanations for these observations may be i) the low knockdown efficiency of $\mathrm{ABCC} 2$; or ii) $\mathrm{ABCC} 2$ is not the sole target of STAT3 in chemoresistance. The ABCC2 siRNAs used in the present experiment consisted of four individual siRNAs that were pooled together, which would minimise the off-target effects of transfection. However, the knockdown efficiency 
was relatively low and therefore no significant difference in cell viability was observed when compared with the control cells. Alternatively, STAT3 may regulate chemoresistance via other targets, besides ABCC2. For example, STAT3 is also involved in the regulation of anti-apoptotic Bcl-2 and Mcl-1 proteins, which may confer chemoresistance in gastric cancer (16). Future experiments should investigate the role of $\mathrm{ABCC} 2$ and $\mathrm{ABCC} 3$ in mediating chemoresistance by determining whether $\mathrm{ABCC} 2$ and $\mathrm{ABCC} 3$ overexpression reverse the effects of YB-1 and STAT3 knockdown on NUGC3 cells. Furthermore, determining how YB-1 and STAT3 regulate the expression of $\mathrm{ABCC} 3$ and $\mathrm{ABCC} 2$, respectively, may be of importance. Using the more advanced clustered regularly interspaced short palindromic repeat/CRISPR-associated protein 9 system to knockout $\mathrm{ABCC} 2$ or $\mathrm{ABCC} 3$ gene expression may be performed to determine the effects on chemoresistance, as the knockdown efficiencies using siABCC 2 and siABCC 3 are relatively low.

The results demonstrated that YB-1 and STAT3 do not mutually regulate the expression of one another, but the two proteins act synergistically in the chemoresistance of gastric cancer cells, suggesting that they may also act together in other biological processes. A previous study reported that STAT3 expression is associated with spread to the lymph nodes in gastric cancer tissues, thus enhancing gastric cancer progression (39). Consistently, the knockdown of STAT3 led to a significant reduction in cell migratory and invasive properties. However, YB-1 has been implicated in the migratory property of NUGC3 cells, but not cell invasion and epithelial-to-mesenchymal transition, complex processes essential to the initial metastatic cascade (40). No significant inhibitory effects of YB-1 were detected with regards to the migratory and invasive properties of NUGC3 cells. Notably, STAT3 knockdown-mediated decrease in cell invasion was further enhanced upon $Y B-1$ knockdown. It was reported that YB-1 prevents apoptosis in Her2-overexpressing breast cancer cells in vitro and promotes tumour growth in mice via the mammalian target of rapamycin/STAT3 signaling pathway (41), indicating a possible cross-talk between YB-1 and STAT3 signaling underlying the pathogenesis of breast cancer. Future experiments to determine the effects of YB-1 and STAT3 downregulation on gastric cancer in vivo may aid in determining the associated signaling pathways of these two molecules.

The present results indicate that YB-1 and STAT3 act synergistically in chemoresistance and cell invasion in NUGC3 gastric cancer cells, thus providing the potential for the development of novel therapeutic interventions targeting these two molecules in gastric cancer.

\section{Acknowledgements}

Not applicable.

\section{Funding}

The present study was supported by the Ministry of Education grants (grant no. MOE2013-T2-1-129 to BHB) and (grant no. MOE T1-2016 Sep-13 to QH). JPL was a recipient of the Ong Hin Tiang Scholarship in Cancer Research.

\section{Availability of data and materials}

All data generated or analysed during the present study are included in this published article.

\section{Authors' contributions}

PJC and TTG designed and performed the experiments. JPL wrote the manuscript and performed the experiments. PK performed the experiments. $\mathrm{QH}, \mathrm{BHB}$ and $\mathrm{GHB}$ conceived the experiment designs and revised the manuscript.

\section{Ethics approval and consent to participate}

Not applicable.

\section{Patient consent for publication}

Not applicable.

\section{Competing interests}

The authors declare that they have no competing interests.

\section{References}

1. Gottesman MM, Fojo T and Bates SE: Multidrug resistance in cancer: Role of ATP-dependent transporters. Nat Rev Cancer 2: 48-58, 2002.

2. Didier DK, Schiffenbauer J, Woulfe SL,Zacheis M and Schwartz BD: Characterization of the cDNA encoding a protein binding to the major histocompatibility complex class II Y box. Proc Natl Acad Sci USA 85: 7322-7326, 1988.

3. Eliseeva IA, Kim ER, Guryanov SG, Ovchinnikov LP and Lyabin DN: Y-box-binding protein 1 (YB-1) and its functions. Biochemistry (Mosc) 76: 1402-1433, 2011.

4. Bargou RC, Jürchott K, Wagener C, Bergmann S, Metzner S, Bommert K, Mapara MY, Winzer KJ, Dietel M, Dörken B, et al: Nuclear localization and increased levels of transcription factor YB-1 in primary human breast cancers are associated with intrinsic MDR1 gene expression. Nat Med 3: 447-450, 1997.

5. Janz M, Harbeck N, Dettmar P, Berger U, Schmidt A, Jürchott K, Schmitt M and Royer HD: Y-box factor YB-1 predicts drug resistance and patient outcome in breast cancer independent of clinically relevant tumor biologic factors HER2, uPA and PAI-1. Int J Cancer 97: 278-282, 2002.

6. Mo D, Fang H, Niu K, Liu J, Wu M, Li S, Zhu T, Aleskandarany MA, Arora A, Lobo DN, et al: Human helicase RECQL4 drives cisplatin resistance in gastric cancer by activating an AKT-YB1-MDR1 signaling pathway. Cancer Res 76: 3057-3066, 2016.

7. Khanna P, Chua PJ, Bay BH and Baeg GH: The JAK/STAT signaling cascade in gastric carcinoma (Review). Int J Oncol 47: 1617-1626, 2015.

8. Kiu $\mathrm{H}$ and Nicholson SE: Biology and significance of the JAK/STAT signalling pathways. Growth Factors 30: 88-106, 2012.

9. Darnell JE Jr, Kerr IM and Stark GR: Jak-STAT pathways and transcriptional activation in response to IFNs and other extracellular signaling proteins. Science 264: 1415-1421, 1994.

10. Catlett-Falcone R, Dalton WS and Jove R: STAT proteins as novel targets for cancer therapy. Signal transducer an activator of transcription. Curr Opin Oncol 11: 490-496, 1999.

11. Wang Z, Si X, Xu A, Meng X, Gao S, Qi Y, Zhu L, Li T, Li W and Dong L: Activation of STAT3 in human gastric cancer cells via interleukin (IL)-6-type cytokine signaling correlates with clinical implications. PLoS One 8: e75788, 2013.

12. Giraud AS, Menheniott TR and Judd LM: Targeting STAT3 in gastric cancer. Expert Opin Ther Targets 16: 889-901, 2012. 
13. Kim DY, Cha ST, Ahn DH, Kang HY, Kwon CI, Ko KH, Hwang SG, Park PW, Rim KS and Hong SP: STAT3 expression in gastric cancer indicates a poor prognosis. J Gastroenterol Hepatol 24: 646-651, 2009.

14. Deng JY, Sun D, Liu XY, Pan Y and Liang H: STAT-3 correlates with lymph node metastasis and cell survival in gastric cancer. World J Gastroenterol 16: 5380-5387, 2010.

15. Kanda N, Seno H, Konda Y, Marusawa H, Kanai M, Nakajima T, Kawashima T, Nanakin A, Sawabu T, Uenoyama Y, et al: STAT3 is constitutively activated and supports cell survival in association with survivin expression in gastric cancer cells. Oncogene 23: 4921-4929, 2004.

16. Huang S, Chen M, Shen Y, Shen W, Guo H, Gao Q and Zou X: Inhibition of activated Stat 3 reverses drug resistance to chemotherapeutic agents in gastric cancer cells. Cancer Lett 315: 198-205, 2012.

17. Lim JP, Shyamasundar S, Gunaratne J, Scully OJ, Matsumoto K and Bay BH: YBX1 gene silencing inhibits migratory and invasive potential via CORO1C in breast cancer in vitro. BMC Cancer 17: 201, 2017.

18. Livak KJ and Schmittgen TD: Analysis of relative gene expression data using real-time quantitative PCR and the 2(-Delta Delta C(T)) Method. Methods 25: 402-408, 2001.

19. Tay WL, Yip GW, Tan PH, Matsumoto K, Yeo R, Ng TP, Kumar SD, Tsujimoto M and Bay BH: Y-Box-binding protein-1 is a promising predictive marker of radioresistance and chemoradioresistance in nasopharyngeal cancer. Mod Pathol 22: 282-290, 2009.

20. Kosnopfel C, Sinnberg T and Schittek B: Y-box binding protein 1 - a prognostic marker and target in tumour therapy. Eu J Cell Biol 93: 61-70, 2014.

21. Huang J, Tan PH, Li KB, Matsumoto K, Tsujimoto $M$ and Bay BH: Y-box binding protein, YB-1, as a marker of tumor aggressiveness and response to adjuvant chemotherapy in breast cancer. Int J Oncol 26: 607-613, 2005.

22. Stephanou A, Brar BK, Knight RA and Latchman DS: Opposing actions of STAT-1 and STAT-3 on the Bcl-2 and Bcl-x promoters. Cell Death Differ 7: 329-330, 2000.

23. Nascimento AS, Peres LL, Fari AVS, Milani R, Silva RA, da Costa Fernandes CJ, Peppelenbosch MP, Ferreira-Halder CV and Zambuzzi WF: Phosphoproteome profiling reveals critical role of JAK-STAT signaling in maintaining chemoresistance in breast cancer. Oncotarget 8: 114756-114768, 2017.

24. Becker TM, Boyd SC, Mijatov B, Gowrishankar K, Snoyman S, Pupo GM, Scolyer RA, Mann GJ, Kefford RF, Zhang XD, et al: Mutant B-RAF-Mcl-1 survival signaling depends on the STAT3 transcription factor. Oncogene 33: 1158-1166, 2014.

25. Saneja A, Khare V, Alam N, Dubey RD and Gupta PN: Advances in P-glycoprotein-based approaches for delivering anticancer drugs: Pharmacokinetic perspective and clinical relevance. Expert Opin Drug Deliv 11: 121-138, 2014.

26. Noguchi K, Katayama K, Mitsuhashi J and Sugimoto Y: Functions of the breast cancer resistance protein (BCRP/ABCG2) in chemotherapy. Adv Drug Deliv Rev 61: 26-33, 2009.
27. Zhang W, Meng Y,Liu N, Wen X-F and Yang T: Insights into chemoresistance of prostate cancer. Int J Biol Sci 11: 1160-1170, 2015.

28. Zhang G, Wang Z, Qian F, Zhao C and Sun C: Silencing of the $\mathrm{ABCC} 4$ gene by RNA interference reverses multidrug resistance in human gastric cancer. Oncol Rep 33: 1147-1154, 2015.

29. Guo T, Yu Y, Yip GW, Baeg GH, Thike AA, Lim TK, Tan PH, Matsumoto $\mathrm{K}$ and Bay BH: Y-box binding protein 1 is correlated with lymph node metastasis in intestinal-type gastric cancer. Histopathology 66: 491-499, 2015.

30. Oda Y, Sakamoto A, Shinohara N, Ohga T, Uchiumi T, Kohno K, Tsuneyoshi M, Kuwano M and Iwamoto Y: Nuclear expression of YB-1 protein correlates with P-glycoprotein expression in human osteosarcoma. Clin Cancer Res 4: 2273-2277, 1998.

31. Koike K, Uchiumi T, Ohga T, Toh S, Wada M, Kohno K and Kuwano M: Nuclear translocation of the Y-box binding protein by ultraviolet irradiation. FEBS Lett 417: 390-394, 1997.

32. Schittek B, Psenner K, Sauer B, Meier F, Iftner T and Garbe C: The increased expression of $\mathrm{Y}$ box-binding protein 1 in melanoma stimulates proliferation and tumor invasion, antagonizes apoptosis and enhances chemoresistance. Int J Cancer 120: 2110-2118, 2007.

33. Yahata H, Kobayashi H, Kamura T, Amada S, Hirakawa T, Kohno K, Kuwano M and Nakano H: Increased nuclear localization of transcription factor YB-1 in acquired cisplatin-resistant ovarian cancer. J Cancer Res Clin Oncol 128: 621-626, 2002

34. Jackson CB and Giraud AS: STAT3 as a prognostic marker in human gastric cancer. J Gastroenterol Hepatol 24: 505-507, 2009.

35. Yu H, Lee H, Herrmann A, Buettner R and Jove R: Revisiting STAT3 signalling in cancer: New and unexpected biological functions. Nat Rev Cancer 14: 736-746, 2014

36. Joo MK, Park JJ and Chun HJ: Recent updates of precision therapy for gastric cancer: Towards optimal tailored management. World J Gastroenterol 22: 4638-4650, 2016.

37. Gong W, Wang L, Yao JC, Ajani JA, Wei D, Aldape KD, Xie K, Sawaya R and Huang S: Expression of activated signal transducer and activator of transcription 3 predicts expression of vascular endothelial growth factor in and angiogenic phenotype of human gastric cancer. Clin Cancer Res 11: 1386-1393, 2005.

38. Fujii T, Seki N, Namoto-Matsubayashi R, Takahashi H, Inoue Y, Toh U, Kage M and Shirouzu K: YB-1 prevents apoptosis via the mTOR/STAT3 pathway in HER-2-overexpressing breast cancer cells. Future Oncol 5: 153-156, 2009.

39. Deng J, Liang H, Zhang R, Sun D, Pan Y, Liu Y, Zhang L and Hao X: STAT3 is associated with lymph node metastasis in gastric cancer. Tumour Biol 34: 2791-2800, 2013.

40. Guo TT, Yu YN, Yip GW, Matsumoto K and Bay BH: Silencing the YB-1 gene inhibits cell migration in gastric cancer in vitro. Anat Rec (Hoboken) 296: 891-898, 2013.

41. Lee C, Dhillon J, Wang MY, Gao Y, Hu K, Park E, Astanehe A, Hung MC, Eirew P, Eaves CJ, et al: Targeting YB-1 in HER-2 overexpressing breast cancer cells induces apoptosis via the mTOR/STAT3 pathway and suppresses tumor growth in mice. Cancer Res 68: 8661-8666, 2008. 